\title{
O PÓS-HUMANO, CYBORGS E A (RE)EVOLUÇÃO DO CORPO EM MEGA MAN MAVERICK HUNTER X
}

\author{
Simão Cireneu Milani Addôr Nunes da Silva ${ }^{1}$ \\ Rosângela Fachel de Medeiros ${ }^{2}$
}

\begin{abstract}
Resumo: Este trabalho propõe a análise da conformação híbrida do robô $X$ (humano e máquina), personagem principal do game Mega Man Maverick Hunter X, lançado em 2005, que é um remake do jogo Megaman $X$, produzido pela Capcom para a plataforma Super Nintendo em 1993. No universo narrativo do game, X é único robô a possuir a capacidade de ter sentimentos, sendo seu projeto o ponto de partida para a criação dos reploids (cyborgs com a capacidade de livre arbítrio), que, como ele,demonstram empatia por todos os seres, sejam humanos ou robóticos. Apesar de X ter o que é considerada a maior "fraqueza" dos humanos: sentimentos, ele é o personagem mais poderoso da série, justamente pela percepção de que esse potencial o torna ilimitado como os humanos; pois enquanto os humanos são capazes de evoluir física e intelectualmente, os robôs estarão permanentemente atrelados à função para a qual foram criados.Para analisar a constituição de $\mathrm{X}$ como uma possibilidade de discussão da perspectiva do pós-humano, utilizamos teorias desenvolvidas por Paula Sibilia (2002) em O homem pós-orgânico, e Lucia Santaella, em Culturas e artes do pós-humano(2003).
\end{abstract}

Palavras-chave: Megaman X. Pós-humano. Cyborgs.

Abstract: This work intends to analyze of the hybrid conformation of the robot $X$ (human and machine), main character of the game Mega Man Maverick Hunter X, released in 2005, which is a remake of the game Megaman $X$, developed by Capcom for the Super Nintendo platform in 1993. In the narrative universe of the game, $X$ is the only robot who has the capacity of owning feelings, being his project the start point for the creation of the reploids (cyborgs capable of having free will), which, like him, demonstrate empathy for every being, being human or robotic. Even though $X$ has what is considered to be the greatest "weakness" of the human being: feelings, he is the most powerful character of the series, just because of the perception that this potential makes him unlimited like the humans. This is because while the humans are capable of evolving physically and intellectually, the robots will be permanently linked to the function to which they were made. To analyze X's constitution as a possibility of discussion of the post-human perspective we are using the theories developed by Paula Sibilia (2002), in The post-organic man, and Lucia Santaella, in Cultures and arts of the post-human (2003).

Keywords: Megaman X. Post-human. Cyborgs.

\footnotetext{
${ }^{1}$ Universidade Regional do Alto Uruguai e das Missões - URI - Campus Frederico Westphalen. Email: simaomilani@gmail.com

${ }^{2}$ Universidade Regional do Alto Uruguai e das Missões - URI - Campus Frederico Westphalen. Email: rosangelamedeiros@gmail.com
} 


\section{A criação, ambientação e narrativa em Mega Man Maverick Hunter $X$}

O jogo Mega Man Maverick Hunter X foi desenvolvido para a plataforma Play Station Portable (PSP) no ano de 2005. Este jogo é um remake (quando um filme, uma novela ou um jogo é produzido novamente com alguns ajustes mais tecnológicos ou mais modernos) do game Mega man $X$ que foi produzido em 1993para a plataforma Super Nintendo Entertainment System (SNES), ambos pela empresa Capcom. Esse jogo foi lançado primeiro no Japão, assim como seus antecessores (os jogos da franquia Mega Man ou Rockman no Japão) e foi um tipo de jogo que inspirou tantos outros mais tarde, por ser bastante inovador.

O personagem Mega Man foi inspirado em uma série de quadrinhos japoneses (mangá), e mais tarde em animação (anime) muito famosa desde os anos 50, a série Astro Boy. O primeiro jogo do Mega Man foi lançado em 1987 no Japão e logo se tornou um dos jogos mais famosos do país, o que o fez ser difundido por todo o mundo. Conforme a história e os anos se passaram, a empresa sentiu necessidade de criar algo um pouco mais sério baseado na mesma forma, por isso criaram a versão Rockman X ou Megaman X.

Nesse remake, os personagens possuem mais falas (além de serem dubladas por atores profissionais, o que dá muita profundidade aos personagens) e até feições em seus rostos, aspectos que eram muito difíceis de serem inseridos na plataforma SNES devido a suas limitações gráficas e sonoras. Graças aos avanços tecnológicos e aos aspectos de hardware do $P S P$, é possível analisar o game sob uma perspectiva completamente nova e mais abrangente. Isso possibilita estudar 0 enredo do jogo por este ter se tornado mais denso e os personagens terem suas personalidades mais evidentes.

No UMD do jogo (mini disco que contém os jogos do console PSP e demais componentes), além do game, é disponibilizado ao jogador um OVA (sigla para Original Video Animation) que conta a história de $\mathrm{X}$, o protagonista da série antes da narrativa principal do jogo. O vídeo é disponibilizado ao jogador assim que se completa a história original uma vez e apresenta os eventos que levaram o início do enredo principal do game e explica as razões de Sigma (principal vilão da série 
Megaman $X)$ em se rebelar contra a humanidade e a razão pela qual $X$ é 0 personagem mais forte da história.

O OVA inicia com uma operação dos Maverick Hunters (Caçadores de Irregulares, em tradução livre) tentando parar a fúria de um mechaniloid (robôs com inteligência sub-humana) que está destruindo construções em Abel City (local onde se passa a narrativa). Enquanto Sigma (que no início era o comandante dos Maverick Hunters) e Zero (um dos melhores Hunters e amigo de X) estão tentando parar o imenso adversário, $X$ é despachado de uma aeronave para tentar um ataque surpresa por cima. Mesmo com um poderoso disparo de $\mathrm{X}$, o mechaniloid continua atacando os Caçadores que estavam por perto e consegue agarrar um deles, tornando a situação muito complicada. Mesmo tentando, Zero não consegue acertar o gerador de energia do robô e por isso sobra para que $X$ tente o disparo de precisão.

No entanto, o mechaniloid está com o Maverick Hunter na frente de seu ponto fraco e isso faz com que $X$ fique indeciso se deve atirar ou não, pois seu companheiro pode ser acertado e morrer. Percebendo que $X$ não iria tomar uma decisão a tempo, o comandante Sigma salta e acerta o gerador do mechaniloid com sua espada laser e corta fora um dos braços do Caçador que estava sendo segurado, porém o liberta do perigo. Nesse ponto da história já podemos observar o que diferencia os dois personagens: um possui um forte senso de humanidade e empatia pelos outros seres, mesmo sendo robóticos, ao passo que o outro não se importa em tomar decisões que ponham em risco o bem estar de outros, desde que a missão seja cumprida.

Mais tarde naquele dia, $X$ e Zero observam que Vile (ou Vava no Japão) está sendo escoltado para a prisão por ter se tornado um Maverick (Irregular, em tradução livre). Nesse momento $X$ pergunta para Zero o que faz com que os Reploids (robôs dotados de capacidade de livre arbítrio) se tornem Mavericks e ataquem outros robôs ou seres humanos. Zero então explica que esse fenômeno ocorre por conta de erro de programação ou falhas no "cérebro" de um Reploid.

O cientista, Dr. Cain, foi quem encontrou a cápsula que continha $X, 0$ primeiro de todos os Reploids. X havia sido selado por Dr. Thomas Light, seu criador pois este pensava que a humanidade não estava pronta para receber um robô que 
podia pensar, agir e tomar suas próprias decisões. Quando o Dr. Cain abriu a capsula, descobriu que $\mathrm{X}$ podia pensar e raciocinar como um ser humano e pensou que esse poderia ser o futuro de toda a humanidade. Esse cyborgé o que a humanidade atual almeja construir, um ser que seja "perfeito", ou seja, possua os melhores aspectos tanto da máquina quanto da carne e isso fica mais claro nas palavras de Santaella (2003):

Ao transgredir as fronteiras que separavam o natural do artificial, o orgânico do inorgânico, o cyborg, por sua própria natureza, questiona os dualismos, evidenciado que não há mais nem natureza nem corpo, pelo menos no sentido que o iluminismo lhes deu (SANTAELLA, 2003, p. 187).

Então, através da estrutura principal de X, Dr. Cain cria outros robôs, os quais chamou de Reploids, que eram robôs que podiam pensar e agir por conta própria, porém, nenhum deles possui a habilidade de ter empatia com outros seres, tal qual X. Curiosamente, Sigma foi o primeiro Reploid criado e é o que mantinha maior contato com Dr. Cain, que, através de aparelhos, estendeu sua vida o máximo que pode para conseguir observar a reação da humanidade em relação a $X$ e os Reploids.

Durante a conversa de Sigma e Dr. Cain, o comandante relata o que houve durante a operação que ocorreu mais cedo. Quando o cientista pergunta como X está se saindo como um Hunter, Sigma responde que apesar de $\mathrm{X}$ mostrar um grande potencial de combate, ele hesita em tomar decisões quando isso pode acarretar danos a inocentes. O cientista concorda com o comandante mas afirma que essa preocupação é a fonte de todo o poder de $X$ e de seu imenso potencial. Cain continua sua resposta dizendo que, mesmo depois de ter criado todos os Reploids, nenhum deles demonstra essa capacidade, nem mesmo Sigma, que é considerado o mais poderoso dos Reploids até então. Para Dr. Cain, essa capacidade de empatia de $X$ pode ser a nova conexão entre robôs e humanos porém não sabe se isso é bom ou ruim e só o tempo responderá essa preocupação.

A história prossegue e um ataque próximo a base dos Maverick Hunters é reportado, algo que preocupa os Caçadores devido à proximidade do ocorrido. 
Quando X e Zero vão investigar o ataque, eles encontram um grande número de Reploids mortos no local e seus ferimentos demonstram que quem os matou possuía grande habilidade de combate e todos os golpes desferidos foram dados em seus pontos fracos. Após reportarem o incidente para o comandante Sigma e retornarem às investigações, outros incidentes ocorrem na cidade e outro mechaniloid gigante está destruindo a cidade, mas dessa vez, próximo à base dos Maverick Hunters. Enquanto $X$ e Zero estão se dirigindo ao local, é mostrado que alguém está libertando Vile de sua prisão. Nesse momento a base de comando ordena que $\mathrm{X}$ e Zero retornem para a base pois Vile havia escapado de sua cela $\mathrm{e}$ ambos os Caçadores observam uma cena muito semelhante à anterior, com diversos Reploids mortos e com todos mortos da mesma forma que os anteriores, nisso Zero começa a ter ideia de quem pode estar por trás de todos esses ataques, o próprio comandante Sigma.

Logo em seguida, os Hunters conseguem localizar o ponto onde os hackers estão conseguindo invadir a base deles, a base de mísseis. Ao chegar ao local, $\mathrm{X} \mathrm{e}$ Zero encontram Sigma, que diz que o culpado dos ataques utilizava o sistema da base de mísseis para conseguir camuflar sua localização e conseguir controlar os mechaniloids. Enquanto Zero verifica os computadores do sistema e questiona Sigma a razão pela qual a base dos Hunters não consegue se comunicar com Sigma, o comandante diz que é para que ele não seja descoberto pelos inimigos e ataca Zero pelas costas, o qual consegue se defender pois já desconfiava que Sigma era o verdadeiro inimigo. O comandante então diz que, apesar de estar impressionado pelas capacidades investigativas de Zero, ele realmente admirava $X$ por ele ter um potencial ilimitado e por ser uma espécie que poderia dar origem a novos e melhores Reploids.

Sigma então consegue segurar Zero e o usa de escudo para que $X$ não o ataque e a situação se torna muito semelhante a cena que inicia a animação. $X$ não consegue atirar com medo de ferir seu amigo e Sigma acaba desferindo um golpe que incapacita Zero. $O$ comandante então consegue segurar $X$ e ameaça lançar todos os mísseis e destruir toda Abel City caso ele não largue suas armas. $X$ então se vê encurralado e larga seu braço onde reside seu canhão laser. Sigma diz que muitos outros estão ao seu lado e lança os mísseis mesmo assim, destruindo toda a cidade e seus habitantes, humanos e robôs, inclusive seu próprio criador, Dr. Cain. 
Sigma atravessa X com seu sabre e diz que para haver evolução, sacrifícios devem ser feitos. Então, X se lembra de todo o seu passado com o Dr. Light e sua promessa de usar seus poderes para proteger a humanidade. Nesse momento, $X$ reúne todas as forças que possui, mostrando seu potencial ilimitado de evolução e desfere um golpe que deixa cicatrizes no rosto de Sigma, porém $X$ não consegue mais se mover pois suas energias se esgotaram. Então, o ex-comandante dos Maverick Hunters finalmente se assume como o líder dos Mavericks e começa sua dominação da raça humana.

Se isso ocorresse de fato, observaríamos a extinção da raça humana e isso não seria impossível de acontecer: as máquinas sobrepujando os humanos, criatura dominando criador. Fukuyama (2000) confirma o que o jogo evidencia, a substituição dos humanos por máquinas que podem pensar e agir por conta própria e que preferem a extinção da raça mais fraca ou "defeituosa". O primeiro jogo, mesmo sem querer, há mais de duas décadas, conseguiu prever esse acontecimento, onde o ser humano procuraria maneiras de transformar suas fraquezas e defeitos através da tecnologia. Nas palavras de Fukuyama:

A biotecnologia fornecerá os instrumentos que nos permitirão realizar o que os especialistas em engenharia social não conseguiram. Neste estágio, teremos encerrado definitivamente a história humana, porque teremos abolido os seres humanos enquanto tais. Então começará uma nova história, para além do humano (FUKUYAMA, 2000, p. 93).

A partir de agora iremos analisar os personagens, a narrativa do game e o que representa os robôs que aparecem durante a narrativa, ou, o "pós-humano". Ponderaremos sobre o que isso representa em nossa vida e o que são essas mudanças que a humanidade está sofrendo, como a tecnologia está interferindo em nosso dia a dia e até que ponto isso está sendo problematizado ou pensado.

\section{O homem pós-orgânico refletido no game}


O personagem principal do game é mostrado como o mais poderoso de todos não por suas habilidades de combate ou seu armamento, mas sim, por possuir a capacidade humana de se importar com outros seres, de possuir empatia. O que Sigma não compreende, e tenta provar que seu criador não tem razão, é que, como um ser que possui uma capacidade que, na visão do comandante, o limita como Maverick Hunter, pode ser sinônimo de potencial ilimitado.

O que o enredo do jogo nos mostra é que, mesmo robôs sendo máquinas "perfeitas", que não possuem as fraquezas humanas, como doenças, enfraquecimento pela idade, perda de memória, cansaço físico ou deficiências, jamais poderão ter todos os sentimentos humanos que possuímos. Seria extremamente difícil inserir nossas formas de nos colocar no lugar do outro ou de lidar com nossos sentimentos dentro de uma máquina.

Oposto à isso, vemos o rumo que a humanidade está tomando. Sibilia (2002), em seu livro O homem pós orgânico, embasa as ideias de que o capitalismo industrial desenvolve estratégias para modelar os corpos utilizando da teleinformática e da biotecnologia para obter mutações drásticas como a invulnerabilidade à doenças e a imortalidade. Isso demonstra que o grande objetivo da ciência atual é nos tornar o mais próximos possível de sermos máquinas que não possuem defeitos, tal qual são os Reploids.

Os humanos estão cada vez mais propensos a adquirir doenças e se tornarem vulneráveis à morte, ironicamente, devido aos grandes avanços tecnológicos e por causa de toda a imensa demanda de consumo que o homem desenvolveu. Mesmo partindo do princípio de que todo ser humano é único e insubstituível e sua estrutura genética é algo extremamente difícil de ser decifrado totalmente pela ciência atual, mesmo sendo, teoricamente, igual uns aos outros, se assemelha aos cyborgs no fato de que possui um "algoritmo" que dá à humanidade seu aspecto de igualdade física. Esse pensamento é confirmado nas palavras de Sibilia (2002):

A linguagem decifrada há menos de cinqüenta anos é universal: todas as células de todos os seres vivos contêm um 'manual de instruções' escrito no mesmo código, o que lhes permite reproduzirse conservando intacta a sua informação genética. O código é idêntico para todos os seres vivos, enquanto que as instruções nele 
escritas variam para cada espécie: em cada caso, elas conformam um conjunto específico de informações chamado genoma. Assim, o tão alardeado Projeto Genoma Humano, que contribuiu grandemente para a popularização dos termos e de toda a retórica ligada à biologia molecular e à engenharia genética, apresenta o corpo humano como uma sorte de programa de computador a ser decifrado (SIBILA, 2002, p.75-76).

Por isso, para tentar solucionar esses novos problemas que ocasionam a diminuição da qualidade de vida e tentar superar as fraquezas e falhas da carne, a ciência procura cada vez mais estender a vida e a juventude dos humanos, desenvolvendo nas pessoas a necessidade de fazer cirurgias rejuvenescedoras e de fazer alterações corporais para que os efeitos da idade ou das doenças. Não apenas quanto ao aspecto humano, mas também quanto a própria natureza em si, vemos tentativas de soluções para todos os problemas que as indústrias e a devastação do meio ambiente vem ocasionando. Sibilia (2011) compara os efeitos dessas mudanças como um jogo de videogame, fechando com o tema proposto por este artigo, que o pós-humano e as transformações que a humanidade está inserindo em si mesma e no seu entorno:

Nesse sentido, recorrendo aos profusos imaginários de nossa indústria cultural, poderíamos apelar à audácia das comparações: pensa-se e age-se, com muita frequência, como se nossos corpos e o planeta inteiro fossem uma espécie de videogame interativo. Mexendo no sistema, portanto, acredita-se que seria possível fechar a porta ao imprevisível, para comandar o destino humano e do mundo em geral, restringindo o insuportável leque de possibilidades contido no futuro (SIBILA, 2011, p. 643).

Já Santaella (2003) em seu livro Culturas e artes do pós-humano trata o corpo como uma figura de barro maleável e mágica; e assume que as aparições de cyborgs no imaginário fílmico e dos games são uma evolução biomecânica do ser humano por ser híbrido entre máquina e matéria orgânica. A autora afirma que os cyborgs são a perfeição que Sigma tanto almeja, um ser que pode tomar decisões por conta própria mas que não possui defeitos ou possa se tornar obsoleto apenas com o tempo, podendo adquirir doenças ou morrer. Isso implica dizer que o ser 
humano não pode estar cumprindo suas funções na sociedade todo o tempo, tendo que ser substituído por outro.

Tudo isso levanta alguns questionamentos como: o que estamos nos tornando? Humanos? Robôs? Cyborgs? Reploids? Qual é o objetivo real em nos tornar cada vez mais máquina reprimindo nossas características humanas? E onde isso irá parar? Nas palavras de Sibilia (2001), há um questionamento se estaríamos em uma dualidade de pensamentos onde teríamos que escolher entre a humanidade, em seus aspectos corporais e sentimentais, ou a robótica: "Isso parece indicar a nova retórica: enquanto o corpo-máquina, característico da era industrial, vai ficando obsoleto; começa a surgir o reluzente corpo-informação, o sujeito da sociedade pós-industrial" (p. 09).

Através das comparações entre o game e a era da inserção das máquinas na vida humana, pudemos perceber o quanto nossa história está convergindo com a do jogo. Estamos sendo espectadores no grande espetáculo da transformação da carne em metal, do cérebro em nanochips. Apesar de no jogo ser mostrada a primeira lei da robótica que é "nenhum robô deverá ferir um humano", isso não foi totalmente seguido justamente pelos Reploids possuírem o livre arbítrio, mesma capacidade que nós humanos possuímos. Já existem robôs que foram desenvolvidos com a capacidade de mentir, então, o que impede que eles possam quebrar essa lei? Estaríamos a salvo apenas colocando nos sistemas dos cyborgs que eles não deveriam machucar humanos? E se algum deles o fizesse? Como seriam julgados? Como humanos ou como máquinas?

Nossas leis e nossa filosofia não nos prepararam para lidar com seres nãohumanos que cometeram crimes humanos. A humanidade teria que desenvolver toda uma nova forma de pensar nesses robôs que, cada dia mais, estão saindo da ficção para se tornar parte do nosso cotidiano. Isso implica pensar cada vez mais 0 rumo que deverão tomar as pesquisas científicas que estão sendo feitas e como serão ponderadas e aprovadas ou não pela humanidade. 


\section{REFERÊNCIAS}

FUKUYAMA, Francis. 0 fim da humanidade. In: VIRILIO, Paul. Estratégia da decepção, Los Angeles: Estação Liberdade, 2000.

SANTAELLA, Lúcia. Culturas e Artes do Pós-humano: Da Cultura das Mídias À Cibercultura. 1a edição. São Paulo: Paulus Editora, 2013.

SIBILIA, Paula. O Homem Pós-orgânico: corpo, subjetividade e tecnologias digitais. Rio de Janeiro: Editora RelumeDumará, 2002.

A técnica contra o acaso: os corpos inter-hiperativos da contemporaneidade. Revista FAMECOS. Porto Alegre, v. 18, n. 3, p. 638-656, set/dez, 2011.

$\mathrm{Sd}$.

Disponível em $<$ http://revistaseletronicas.pucrs.br/ojs/index.php/revistafamecos/article/download/10 373/7273> . Acesso em 05 mar 2017.

Rumo à imortalidade e à virtualidade: A construção científico-tecnológica do homem pós-orgânico. Anais do XXIV Congresso Brasileiro da Comunicação. INTERCOM - Sociedade Brasileira de Estudos Interdisciplinares da Comunicação. Campo Grande: MS, set 2001. Sd. Disponível em <http://www.intercom.org.br/papers/nacionais/2001/papers/NP8SIBILIA.PDF>. Acesso em 05 mar 2017. 